\title{
Vulnerabilidade e sofrimento no trabalho do Agente Comunitário de Saúde no Programa de Saúde da Família*
}

\author{
VULNERABILITY AND SUFFERING IN THE WORK OF A COMMUNITY HEALTH \\ AGENT IN THE FAMILY HEALTH PROGRAM
}

\author{
VULNERABILIDAD Y SUFRIMIENTO EN EL TRABAJO DEL AGENTE COMUNITARIO \\ DE SALUD EN EL PROGRAMA SALUD DE LA FAMILIA
}

Wânia Regina Veiga Martines', Eliane Corrêa Chaves²

*Extraído da disser-
tação“Compreendendo
o processo de sofri-
mento no trabalho do
Agente Comunitário
de Saúde no Progra-
ma de Saúde da
Família”, Escola de
Enfermagem, Univer-
sidade de São Paulo
(EEUSP), 2005.
1 Enfermeira. Diretora
Técnica da UBS Vila
Reunidas I, Programa
de Saúde da Família,
Fundação Zerbini,
Secretaria Municipal
da Saúde de São
Paulo. São Paulo,
SP, Brasil.
wanregina@
terra.com.br
2 Enfermeira. Profes-
sora Doutora do
Departamento de
Enfermagem Médico-
Cirúrgica da EEUSP.
São Paulo, SP, Brasil.
eccsp@yahoo.com.

\section{RESUMO}

A pesquisa, de natureza qualitativa, teve como núcleo de interesse investigativo as representações e as significações que um grupo de Agentes Comunitários de Saúde (ACSs) possui acerca das vulnerabilidades para o sofrimento no trabalho a que estão expostos, assim como as próprias manifestações deste sofrimento ao desempenharem suas ações relativas ao Programa de Saúde da Família (PSF).A entrevista semi-estruturada com um grupo de ACSs, explorou o significado de ser ACS e a percepção da organização do trabalho; a análise foi embasada no referencial teórico-metodológico da hermenêutica e nas teorias relacionadas à psicodinâmica do trabalho. Os achados mostram a existência de uma importante vulnerabilidade ao sofrimento, gerada principalmente pela ideação idealizada da própria prática e pela escassa perspectiva de rearranjo dos ingredientes constitutivos da organização do trabalho, já que este profissional depende de fatores alheios ao seu espectro de alcance, que inclui as limitações do modelo assistencial proposto pelo PSF.

DESCRITORES
Pessoal de saúde.
Condições de trabalho.
Programa Saúde da Família.

\section{ABSTRACT}

This qualitative research was aimed at investigating the representations and significations that a group of community health agents (CHAs) has concerning the vulnerabilities for suffering in their work to which they are exposed to, as well as the manifestations of this suffering as they perform their actions in the Family Health Program (PSF, in the Portuguese language acronym). The semistructured interview with the group of agents explored the meaning of being a CHA and their perception of their work organization; the analysis was based on the hermeneutics theoreticalmethodology referential and on the theories related to labor psychodynamics. The findings show the existence of considerable suffering vulnerability, generated by an idealized ideation of the practice and by the scarce perspective for rearranging the constitutive ingredients of work organization, since these professionals depend on factors that are beyond their grasp, which include the limitations of the assistential model proposed by the PSF.

\author{
KEY WORDS \\ Health personnel. \\ Working conditions. \\ Family Health Program.
}

\section{RESUMEN}

La investigación, de naturaleza cualitativa, tuvo como centro de interés un grupo de Agentes Comunitarios de Salud (ACSs) sobre las vulnerabilidades para el sufrimiento en el trabajo a que están expuestos, al desempeñar sus acciones profesionales en el Programa Salud de la Familia (PSF).La entrevista semi estructurada exploró el significado de ser ACS y la percepción de la organización del trabajo; el análisis fue efectuado con base al referencial teórico-metodológico de la hermenéutica y de las teorías relacionadas a la psicodinámica del trabajo.Los descubrimientos muestran la existencia de una importante vulnerabilidad al sufrimiento, generada principalmente por la creación de las ideas idealizadas de la propia práctica y por la escasa perspectiva de la disposición de los ingredientes constitutivos de la organización del trabajo, siendo que el profesional depende de factores ajenos a su espectro de alcance, que incluyen las limitaciones del modelo asistencial propuesto por el PSF.

\section{DESCRIPTORES}

Personal de salud.

Condiciones de trabajo.

Programa Salud de la Familia. 


\section{INTRODUÇÃO}

As complexas transformações políticas, econômicas e socioculturais historicamente, foram, ao longo do tempo, prescrevendo de forma genérica (por meio dos grandes modelos organizacionais) e ou singular (circunstâncias organizacionais locais e particulares de cada trabalhador) contextos de adaptação e inadaptação do homem em sua relação com o trabalho.

O estudo das repercussões que o trabalho exerce sobre o homem, e como este lida com a complexidade do contexto laboral, tem sido objeto de estudo de várias áreas do conhecimento nas últimas décadas.

É importante e oportuna a observação que o trabalho nunca é neutro em relação à saúde e favorece, seja a doença, seja a saúde, exercendo, desta forma, influências também favoráveis a realização e satisfação, inserindo o homem em um mundo relacional, de trocas, de desenvolvimento de uma inter e intra-subjetividades sadias, de reconhecimento e valoração social ${ }^{(1)}$.

Há trabalhos publicados que reforçam a concepção do significado do trabalho, alertando a respeito das causas do sofrimento psíquico, pois devem ser buscadas nas atividades humanas geradoras de significado, e uma delas é o trabalho( ${ }^{(2)}$.

Em certa medida, não há como desconsiderar que a organização do trabalho e a gestão em saúde foram cronologicamente atravessadas por traços do modelo taylorista, com a fragmentação do conhecimento e das práticas (organização parcelar do trabalho, especializações dentro de cada categoria profissional, centralização no modelo biomédico), burocratização, normatizações técnicas, sistemas de controle de produção de serviços e procedimentos, mecanismos de alienação e imobilidade, que até hoje seguem exercendo profunda influência nos conceitos e processos de trabalho ${ }^{(3-4)}$.

Assim, clientela e trabalhadores comumente deparam-se com realidades de trabalho instituídas, prescritas, podendo ser concebidas como antigos e modernos taylorismos ${ }^{(3)}$.

As experiências, na atenção básica no Brasil, têm presenciado a subordinação dos modelos à doença e à intervenção médica individual, submersos em estruturas de organização técnica e administrativa, colocadas e recolocadas a serviço desse ideário, praticamente, isentos de discussões democratizadas que pudessem expandir-se e efetivar-se a ponto de captar as reais necessidades de usuários e trabalhadores.

Contrariando a estabilidade do paradigma historicamente instituído em saúde - da maciça valorização da tecnologia hospitalar e da tecnologia médica - na pretensão de criar uma outra lógica em saúde, assistimos à importante transformação a que se propôs o Programa de Saúde da Família (PSF) no Brasil na tentativa de reorganizar e qualificar a atenção primária, apontada pelo Sistema Único de Saúde.

Em 1991, por meio do convênio entre a Fundação Nacional de Saúde e as Secretarias de Estado da Saúde, é criado o PACS - Programa de Agentes Comunitários de Saúde - equipe constituída na proporção de um enfermeiro instrutorsupervisor para 30 ACS, lotados em uma Unidade de Saúde, entendido como uma estratégia transitória para o $\mathrm{PSF}^{(5)}$, implantação que ocorreu, inicialmente, na Região Nordeste, frente à epidemia do cólera, com impacto significativo nos indicadores, quando comparados aos de regiões não cobertas pelo Programa ${ }^{(6)}$.

A Organização das Nações Unidas (ONU) elegeu o ano de 1994 como Ano Internacional da Família, assim, o Ministério da Saúde cria no Brasil o Programa de Saúde da Família, procurando seguir as diretrizes previstas no SUS, sobretudo, tomando a família como eixo estrutural no que diz respeito aos fatores determinantes e condicionantes do processo saúde-doença da população $\operatorname{assistida~}^{(7)}$.

A chamada equipe básica ou nuclear concebida no PSF é composta por um médico generalista, um enfermeiro, dois auxiliares de enfermagem e cinco a seis ACS e, dependendo do município, conta também com a retaguarda de profissionais da equipe de saúde bucal, saúde mental e reabilitação, e os dados de atendimento e produção dos profissionais, assim como aqueles coletados pelo ACS nas visitas domiciliares devem alimentar o SIAB - Sistema de Informação de Atenção Básica ${ }^{(8)}$.

No PSF, o trabalho caminha pelo viés da assistência integral, entendida por ações preventivas, de promoção da saúde e curativas, nas quais se busca a qualidade de vida global e a cidadania do usuário em cada etapa do processo de atenção, atrelada à visão de equipe interdisciplinar, contando com um trabalho de base feito pelo ACS que realiza o monitoramento (diagnóstico local situacional) de forma contínua, sob supervisão do enfermeiro.

Passa a existir um novo personagem, o ACS, que, curiosamente, faz parte dessa população e trabalha para ela, com ela; supõe-se que é quem conhece as formas cotidianas de viver, de significar a vida e de se comportar das famílias locais. A profissão foi criada pela Lei 10.507 de 10/07/02, sancionada pelo presidente Fernando Henrique Cardoso, sendo que o Decreto no. 3.189 de 04/10/99 fixa as diretrizes para o exercício da atividade. 
A estratégia do PSF estrutura-se apoiada no Sistema Único de Saúde, incorporando as diretrizes de universalização, descentralização e participação da comunidade e anuncia-se com princípios complementares : caráter substitutivo ao modelo tradicional de atenção primária, antes centrado prioritariamente na relação médico-paciente e no atendimento individual; integralidade e hierarquização (encontrando-se dentro do sistema de referência e contra-referência da rede); territorialização e cadastramento da clientela; equipe multiprofissional ${ }^{(9)}$.

Para elucidar no que a organização do trabalho, considerada inédita, contribui para os trabalhadores do PSF e, dentre eles, o Agente Comunitário de Saúde (ACS), recorre-se à reflexão cuidadosa da psicodinâmica do trabalho, quando esta concentra sua concepção de sofrimento e de psicopatologia do trabalho na relação entre homem e organização do trabalho, que é a maneira como ocorre a divisão de tarefas, como se dá a formação de hierarquias e de sistemas de controle, qual a flexibilização existente para que o homem transite em meio à normatização e dinâmica organizacional e, fundamentalmente, qual é o significado do trabalho para o sujeito que o executa ${ }^{(10)}$.

Na prática, percebe-se que a organização do trabalho no PSF está relacionada com a qualidade da relação vincular da equipe entre si e desta com as famílias.

Entretanto, vale ressaltar que diante das necessidades, as pessoas da comunidade buscam em primeiro lugar o ACS, quer seja uma informação, uma reclamação ou a solução de um problema mais grave e dele esperam uma resposta, em uma relação de cobranças e exigências nem sempre tranqüila; por este motivo, a opção foi concentrar esta pesquisa no sofrimento específico do ACS, muito baseada na quantidade e na intensidade de estímulos a que este é submetido e nos muitos recursos que dele são exigidos a fim de concretizar a Vigilância à Saúde do território sob sua responsabilidade, o que corresponde à cerca de 200 famílias.

Com relação ao perfil e delimitação do papel profissional, espera-se que tenha bom relacionamento com a comunidade local (aceitação), saiba trabalhar as questões relacionadas a preconceitos, sigilo e ética profissional, tenha facilidade de comunicação, que consiga se integrar à equipe interdisciplinar no processo de Vigilância à Saúde, capacidade de organizar-se, planejar e priorizar ações, de modo a realizar a cobertura sistemática da área (uma visita domiciliar por família/mês), e acompanhar os grupos de risco - individuais e coletivos - notificando a equipe, mediante problemas identificados, além de integrar-se à realização do diagnóstico local para controle do perfil de morbimortalidade.

Deve também desenvolver as ações básicas, como incentivo ao aleitamento materno, início precoce das gestantes ao pré-natal, prevenção das doenças de maior prevalência, busca ativa aos portadores de doenças crônico- degenerativas que estão sem acompanhamento, identificação precoce de doenças de notificação compulsória, assim como desenvolver o conceito de humanização da assistência e participação popular como co-responsável nas ações e no controle da qualidade da assistência proposta.

Com freqüência, há uma desproporção entre o perfil real $\mathrm{X}$ perfil esperado, que desencadeia uma série de esforços do ACS para superar as incompetências identificadas, tanto pelo próprio ACS, como pela equipe de saúde da família e até pela comunidade atendida, após algum tempo de trabalho. A partir daí, é gerado um período de adaptação do perfil, centrado nos problemas mais evidentes. Este descompasso existe de forma muito nítida e acredita-se que é uma das maiores causas de sofrimento cotidiano.

Também observa-se no cotidiano que expectativas de várias naturezas são depositadas no ACS como: observação, identificação, iniciativa, busca, difusão dos conhecimentos, integração, incorporação de valores, produtividade, postura profissional equilibrada, dentre outras, que, quando não correspondidas, parecem causar desdobramentos significativos, afetando o profissional estrutural do programa, no que diz respeito à exposição à vulnerabilidades para o sofrimento no trabalho.

Apreendida em um conceito mais genérico como circunstância de suscetibilidade ou de exposição a riscos, que pode desencadear e determinar um agravo, a vulnerabilidade acena com fatores individuais, sociais, institucionais e ambientais que podem ser representados por recursos combinados entre si (grau de consciência, comportamento individual, acesso à informação, serviços, bens culturais), a fim de proteger o indivíduo diante da ocorrência do agravo ou, contrariamente, submetê-lo à condição de ameaça ${ }^{(11)}$.

\section{OBJETIVO}

Analisar as vulnerabilidades e o sofrimento referido pelo ACS no cotidiano do trabalho, identificados a partir do significado de ser ACS e da percepção em torno da organização do trabalho.

\section{MÉTODO}

A proposição da pesquisa no estrito sentido metodológico foi anunciar-se como de natureza qualitativa e manter como nucleariedade e objeto de estudo o processo de sofrimento no trabalho do ACS.

A intenção foi fixar-se teórica e metodologicamente à hermenêutica, entendendo-a como um desdobramento instrumental da fenomenologia, como um meio sistemático de aproximação do fenômeno ou do objeto e que se atém especificamente ao sentido expresso na linguagem. 
Entendida como um esforço de retorno e concentração à essência do significado, lança mão da estratégia interpretativa da linguagem a ponto de tornar sua mensagem compreensível, sendo necessário utilizar, por parte do intérprete, um horizonte de aproximação apreensível, circunstancialmente delimitado quanto à perspectiva histórica, cultural e temporal, à qual a mensagem está conectada ${ }^{(12)}$.

Considerando a perspectiva hermenêutica, os achados foram objetos de apreensão, não como uma tentativa totalitária de apreensão e representatividade da realidade pesquisada, mas como apreensões às quais as pesquisadoras atribuiram caráter de destaque, já que resultam de uma possível e singular leitura desta realidade, baseada no sentido expresso na linguagem dos sujeitos, os ACS.

A sustentação teórica, para a discussão dos significados obtidos, se fez a partir, principalmente, dos pressupostos da psicodinâmica do trabalho, que, incorporando alguns conceitos da psicanálise, utiliza-se de uma abordagem mais abrangente do sofrimento, à medida em que considera a qualidade de interpenetração do universo do sujeito e a organização do trabalho, como importante elemento a determinar as experiências de prazer e sofrimento do trabalhador.

Desta forma, a opção metodológica foi localizar sistematicamente nas falas dos entrevistados pontos de saturação que configurassem grandes categorias de significação, supondo que os conteúdos representacionais viessem a se repetir e pudessem agrupar mais coerentemente os dados e, assim, facilitar a análise à luz das teorias eleitas, dialogando com os achados.

A coleta de dados foi realizada por meio de entrevista semi-estruturada com um grupo de 12 ACS de uma Unidade Básica de Saúde (UBS) localizada no município de São Paulo, que trabalha exclusivamente com o modelo do PSF; as perguntas norteadoras mantiveram foco no significado de ser ACS e na organização do trabalho no PSF.

Neste estudo, a entrevista semi-estruturada fixa-se, portanto, como instrumental identificatório, podendo subsidiar a convergência ou não para a validação das hipóteses destacadas como precursoras do sofrimento no trabalho, após serem transcritas e submetidas ao processamento metodológico e teórico dos achados, à luz do referencial teórico central, que é a psicodinâmica do trabalho.

A pesquisa respeitou as exigências da Resolução no 196/ 96, do Conselho Nacional de Saúde, tendo a aprovação do Comitê de Ética em Pesquisa da Escola de Enfermagem da USP.

\section{DISCUSSÃO}

Das categorias de significação, no total de 21 (12 relacionadas à vulnerabilidade e 9 ao próprio sofrimento referi- do), optou-se, neste trabalho, por conferir destaque à 8 categorias de vulnerabilidade: 1) a ideação idealizada da própria prática; 2) a vinculação empática disfuncional com o usuário; 3) o registro de informações e burocracia como obstáculos; 4) o distanciamento entre o projeto proposto e sua implantação; 5) o deslocamento da responsabilidade sobre as limitações da resolutividade do PSF; 6) a dimensão de precariedade do modelo de supervisão do ACS; 7) relações intra-equipe inadequadas, relacionamento interpessoal conflitivo e 8) compreensão equivocada do trabalho interdisciplinar.

Ficou evidente que um elemento importante de vulnerabilidade repousa fundamentalmente na ideação idealizada da própria prática:

Ser ACS é você ter a chance de mudar a sua comunidade, estar vendo um trabalho que, às vezes, não saía na comunidade [...] O ACS tem todo um auxílio do Posto de Saúde onde ele trabalha. A gente pode estar levando o médico [...] é mudar a vida do cidadão, cuidar da saúde dele, saber que o direito dele está reservado pra ele [...] É você fazer a diferença, é você se humanizar com quem mora do seu lado [...] Você tem uma força. Você ganha uma força, assim [...] por fazer parte do PSF você ganha responsabilidade. Você ganha força pra estar movimentando a comunidade, estar mudando de certas formas [...] e lidar com os sentimentos todo dia [...] Ouvir também reclamação, ouvir bastante [...] Eu estou numa fase de animação, mas, é triste a gente estar lutando, lutando, lutando e a gente poder só dar esperança prá pessoa. A maioria dos problemas não depende só da gente, depende de vários órgãos [...] A gente sabe que tá podendo resolver, só que é muita burocracia, às vezes, prá tudo e aí a gente [...] a única coisa é que a gente vai lá dar esperança [...] (ACS 7)

Mostra-se fértil no sentido de criar e alimentar um complexo conflito, baseado sobretudo na ambigüidade, no confronto com a realidade: o ACS tenta se equilibrar, mas não consegue, na idéia primária de onipotência diante da comunidade que assiste (qualidade, transformação, resultado, humanização, resolutividade, poder, doação), ao mergulhar na fantasia e desconsiderar a viabilidade dos recursos necessários além dos seus próprios; isso, claramente, cria repercussões físicas e intrapsíquicas.

O conflito pode ser avaliado com a ajuda do conceito de carga psíquica do trabalho, que nada mais é do que o conjunto de manifestações decorrentes da qualidade de destinação da energia psíquica, conforme a organização do trabalho permite/ flexibiliza o uso das aptidões psíquicas e psicomotoras do sujeito, revertendo em acúmulo desta carga, quando as aptidões estão impedidas de serem utilizadas (o que torna o trabalho fatigante) ou favorecendo a descarga da energia (trabalho equilibrante), já que é na organização do trabalho que repousa a versatilidade dos mecanismos de adaptação do trabalhador ao conteúdo da tarefa. A carga psíquica é de natureza qualitativa, subjetiva, não 
mensurável caracterizada por desdobramentos de ordem predominantemente psicoafetiva-relacional ${ }^{(10)}$.

As descrições de vivências depressivas, de angústia, frustração e desamparo nos relatos foram recorrentes, visivelmente relacionadas ao fato do ACS se cobrar ostensivamente de modo a atender e superar as expectativas - as reais e as idealizadas. As da comunidade, as dele e as da equipe, uma tríade que constrói e reforça componentes de idealização com relação aos limites de atuação do ACS.

Este complexo de complementaridade que, provavelmente, ocorre na relação entre ACS, usuários e demais profissionais de saúde, parece ser finalizado e mais firmemente constituído pela vertente da instituição que, por diversas vias e de diversos modos, reforça a visão idealizada.

Na idéia de missão do Agente Comunitário de Saúde ser o agente de mudanças, a ordem dos empecilhos fica praticamente inexplorada, como se na conjugação desses verbos, os recursos oferecidos pela atuação dos demais profissionais da equipe não fizessem parte, como também pela estrutura da UBS, pelo dimensionamento desfavorável do número de famílias (que ultrapassa o número preconizado pelo Ministério da Saúde) e pelo déficit de agilidade da rede de atenção complementar do SUS local - dificuldade de acesso a especialidades e recursos de maior complexidade, diagnósticos e outros da atenção secundária e terciária.

A Vigilância à Saúde, necessária para subsidiar a idéia de transformação, sem dúvida alguma, passa pelo encadeamento de todos esses recursos. Desse modo, seria demasiadamente ingênuo, pensá-la como missão isolada do ACS.

Os resultados deste estudo apontam para o fato de que, com probabilidade, houve um acoplamento das idéias, fantasias, ideologias e expectativas dos vértices constitutivos desse conjunto, de tal modo que o ACS mostra-se convicto de que a missão de fato é dele, expressando seu sofrimento em não conseguir realizá-la, na maioria das vezes, sem relativizar sua responsabilidade.

Constrói-se, portanto, um equívoco de difícil manejo no cotidiano: as ações do ACS são propostas como primárias, mas a equipe e o Programa trabalham sob o paradigma da integralidade.

A realidade de intervenção não é simples: há de se destacar as demandas de saúde mental, de atendimento odontológico, de fisioterapia e reabilitação, de pacientes acamados e seus cuidadores, aquelas conseqüentes da violência urbana e familiar, as ambientais: lixo, ratos, enchentes, dengue... com as quais, sem exceção, o ACS tem de lidar. Em função disso, a Vigilância à Saúde, o poder de transformação e a tônica da missão do ACS têm de ser repensados com ele e por ele.

Ao introduzir aqui a lógica do espaço interseçor ${ }^{(a)}$, mais que a concretude instalada no momento do encontro entre trabalhador de saúde (produtor de atos assistenciais) e usuário (consumidor dos atos), há de se considerar o encontro e a produção mútua de subjetividades dos sujeitos que trazem suas leituras e representações diferenciadas em torno do critério de necessidade implícita e já instituída por ambos. Por isso, interesses e intenções nem sempre são consonantes na dimensão das decisões e da satisfação dessas necessidades. Contrariamente ao que se pensa, a escuta e a negociação das necessidades podem ocorrer com baixo nível de conflito ${ }^{(13)}$.

Neste estudo, os relatos obtidos evidenciaram a existência de mecanismos peculiares, do ACS competindo consigo mesmo, com seus limites, seus resultados, projetos, aspirações e negando-se a entregar-se ao sentimento de fracasso e frustração, perante a comunidade, ainda que seu desempenho seja freqüentemente confundido com a capacidade de produção de acesso do sistema de saúde e de absorção da demanda, em uma UBS na qual o simples dimensionamento do número de famílias por equipe está em profundo desequilíbrio.

Ao ancorar a lógica na psicopatologia do trabalho, obtém-se :

No que diz respeito à relação do homem com o conteúdo significativo do trabalho, podem-se considerar, esquematicamente, dois componentes: o conteúdo significativo em relação ao Sujeito e o conteúdo significativo em relação ao Objeto. No conteúdo significativo do trabalho em relação ao sujeito, entra a dificuldade prática da tarefa, a significação da tarefa acabada em relação à uma profissão (noção que contém ao mesmo tempo a idéia de evolução pessoal e de aperfeiçoamento) e o estatuto social implicitamente ligado ao posto de trabalho determinado. O conteúdo significativo do trabalho em relação ao objeto: ao mesmo tempo que a atividade de trabalho comporta uma significação narcísica, ela pode suportar investimentos simbólicos e materiais destinados a um outro, isto é, ao Objeto(1).

Os universos concreto e subjetivo dos ACS deste estudo, provavelmente, estejam sendo atravessados pela dupla natureza do significado do trabalho. Pode-se ainda estender esta reflexão, a fim de contemplar o investimento simbólico na equipe de trabalho, na qual o ACS demonstrou necessidade de ser reconhecido e aceito em uma certa circulação narcísica necessária.

O ACS referiu esgotar suas habilidades para lidar com o tempo, com o excesso de tarefas, com as críticas, com a dificuldade de preservar o espaço familiar e o tempo de descanso, com a incompletude e a desqualificação de seu trabalho e com o cansaço físico. Novamente, experimenta os sentimentos de frustração, ansiedade, solidão, revolta e uma certa inutilidade, como se todo o esforço tivesse sido em vão.

(a) O termo espaço interseçor é considerado, pelo autor, como uma fusão conceitual de interseção e intervenção 
A vinculação empática disfuncional com o usuário foi interpretada, como fonte de desdobramento de sofrimento, sendo que o imaginário em torno da noção de vínculo parece estar relacionado à própria representação que os ACS demonstraram ter sobre os sujeitos e ações relacionadas à atividade de cuidar, e à própria organização estrutural do PSF, que dificulta o estabelecimento de limites e limitações necessários para qualquer prática profissional.

Já o que se observou por meio dos depoimentos dos ACS deste estudo é que eles não têm sido capazes de discernir sobre seus limites, pelo menos, aqueles relacionados à criação de vínculos, doação de tempo e empenho, reciprocidade, entre outros, o que os levam a vivenciar os sentimentos de impotência, cansaço e solidão, mais que isso criam um terreno de tensões na vida pessoal, de difícil manejo, e pior, de difícil desconstrução, visto que as famílias já estão condicionadas pelo comportamento ilimitado e heróico do ACS:

[...] eu achei que fosse uma coisa mais formal [...] Achei que não haveria envolvimento [...] Vi que era uma coisa completamente diferente, porque não tem como não se envolver com as pessoas, porque nós somos seres humanos. Não consigo ser muito assim [...] racional [...] com as pessoas mais carentes com problemas mais acentuados de pobreza mesmo [...] Quando me deparava com esse tipo de coisa, eu ficava, assim, meio sem saber como agir, uma sensação de impotência, porque o meu trabalho se limitava ali. Na verdade, eu queria arrumar dinheiro para o gás para aquela pessoa. Eu queria ir lá, sabe, dar um jeito de colocar a água [...] eu ficava assim à noite. Eu ficava impressionada, eu ficava pensando [...] aquela sensação de não poder ajudar. Na verdade, entrar na vida da pessoa, e aquela pessoa confiar tanto em mim, para ela colocar todos os problemas dela, e eu não poder ajudar, talvez, quando ela estava falando tudo aquilo para mim, ela não estava simplesmente esperando uma consulta. Ela estava esperando algo mais de mim que não dava para mim fazer [...] (ACS 4)

A vulnerabilidade do registro de informações e burocracia como obstáculos, no caso específico deste estudo, demonstrou que a falta de clareza sobre a vocação e a utilidade do SIAB, por parte do ACS, parece ser consistente, de tal forma que em vários momentos, ele foi referido como atividade burocrática que obstaculiza o desempenho de atividades realmente importantes.

Com relação ao distanciamento entre o projeto proposto e sua implantação, observou-se que os ACS fizeram referência em seus depoimentos a estes dois momentos na organização do trabalho no PSF, passado e presente, vinculando o primeiro momento ao que eles acreditavam ser o modo mais adequado de ocorrer a assistência ao usuário e o segundo momento ao motivo pelo qual se decepcionaram em grande parte com a proposta do PSF:

[...] a gente tinha um programa de qualidade mesmo, a gente está perdendo e é [...] deixa a gente muito [...] Eu fico muito triste por isso [...] essa coisa de atendimento, atendimento, atendimento em consultório. Já foi provado, durante todos esses anos aí, e a gente já viu que, em pouco tempo de prevenção e promoção, a gente consegue, é prazeiroso para a gente [...] sabendo que o programa tem um ideal. A ideologia desse programa [...] na prática é outra, é muito difícil, muito difícil mesmo [...] (ACS 9)

A bem da verdade, nas dimensões tecnológica e política, o PSF é considerado uma inovação substitutiva na atenção básica, conforme tenta se movimentar criativamente em direção ao núcleo familiar, trabalhar em equipe, escutar e considerar o saber e a participação popular, sair da Unidade Básica de Saúde e realizar intervenções mais ousadas na área, e de, uma forma geral, aproximar-se da integralidade da assistência.

O PSF tenta desconstruir a centralização na UBS, mas o modelo clínico, infelizmente, ficou e ainda se mostra como o grande centralizador, o grande organismo de sustentação da assistência (independente se ocorrer dentro ou fora da UBS); é certamente um dos motivos, senão o principal, que induz o ACS ao sentimento de cansaço e desilusão no presente.

Com base nos relatos desta pesquisa, constatou-se que o processo de trabalho fez com que o ACS deslocasse para si, e a comunidade deslocasse para o ACS (portanto, é um duplo deslocamento), a responsabilidade em dar respostas ao usuário com vistas a sustentar o princípio de assistência integral que tanto é divulgado pelo PSF, ou seja, há um deslocamento da responsabilidade sobre as limitações da resolutividade do PSF.

O relato dos ACS ajudou a consagrar a questão de que estes ACS lidam com a produção de soluções possíveis, a produção de cuidados comunitários, mediante uma realidade possível nem sempre compatível com o desejo do usuário, pois, com freqüência mantém-se no mecanismo habitual de responsabilizar o interlocutor (o elo) pela insatisfação desse desejo:

[...] Quando a gente chega na visita, quem escuta é a gente [...] Isso já me traria, assim, uma grande satisfação, de poder trabalhar com respostas, com respostas, que coisa que a gente não tem é resposta para o usuário [...] (ACS 8)

O modelo de supervisão do ACS, sob responsabilidade do enfermeiro, conformou-se em uma dimensão de precariedade, segundo os depoimentos dos ACS, sendo necessário integrar no mesmo modelo três perspectivas: oferta de capacitação, manutenção da educação continuada e acolhimento de demandas psicoafetivas.

A oferta de capacitação e educação continuada são remetidas a uma realidade instável e descontínua, conforme o programa de capacitação priorize médicos e enfermeiros e não sistematize com maior cuidado e especificidade o preparo do ACS.

O acolhimento das demandas psicoafetivas - muito impregnadas pelos empecilhos de natureza técnico-estrutural 
- dependerá do tipo de liderança exercida pelo enfermeiro: alguns têm uma liderança inexpressiva, difusa; outros recorrem a lideranças autoritárias, meramente controladoras/ repressoras e, logicamente, uma parcela dos enfermeiros consegue oferecer um suporte razoável, identificado com as necessidades do ACS. Esta descrição apareceu de forma explícita no relato dos ACS desta pesquisa.

A dimensão das relações intra-equipe inadequadas, relacionamento interpessoal conflitivo mostrou-se bastante relacionada à compreensão equivocada do trabalho interdisciplinar.

Pelos relatos dos ACS, percebe-se que existem muitos conflitos que devem ser trabalhados pelas equipes e, na verdade, parecem girar em torno da incompreensão e inaceitação de diferenças, tanto do ponto de vista comportamental humano de cada um (gestuais psicoafetivos), como do ponto de vista de posicionamentos técnicos, no momento de negociar e definir o que é prioridade, se é atendimento clínico ou é promoção, por exemplo.

Pelas linhas de fracionamento (técnicas e pessoais), ficou evidente a mentalidade de que cada um deve fazer seu pedaço, sem interferir muito no do outro, que se traduz pelo aglomerado de profissionais que, ocasionalmente, se encontram, mas não se integram na necessária interdisciplinariedade; por vezes, em franco mecanismo de disputa ou tentando ignorar as linhas de fracionamento e continuar trabalhando do jeito que dá.

Alguns autores ${ }^{(14)}$ propõem um novo olhar sobre a tecnologia em saúde, que sustenta o processo produtivo, orientando-o na direção da produção cotidiana de bens/ produtos e relações na dimensão institucional:

\section{[...] classificamos as tecnologias envolvidas no trabalho em saúde como: leve (como no caso das tecnologias de relações do tipo produção de vínculo, autonomização, acolhimento, gestão como uma forma de governar pro- cessos de trabalho), leve-dura (como no caso de saberes bem estruturados que operam no processo de trabalho em saúde, como a clínica médica, a clínica psicanalítica, a epidemiologia, o taylorismo, o fayolismo) e dura (como no caso de equipamentos tecnológicos do tipo máquinas, normas, estruturas organizacionais) $[\ldots]^{(14)}$.}

Dada esta perspectiva, nesta pesquisa, verifica-se que a combinação do comportamento que se espera do ACS - escuta, envolvimento, responsabilização, acolhimento , humanização - remete-o todo tempo à capacidade de manter (ou não) o bom equilíbrio vincular, subordinando sua ação ao uso da tecnologia leve.

É possível tomar esta tecnologia como pano de fundo para possibilidades aproximativas e contratuais, em razão dos múltiplos encontros humanos possibilitados a partir do
ACS, não só para seu uso exclusivo, mas, sobretudo, para uso de toda uma série de profissionais que depende da intermediação cooperativa do ACS para chegar até as famílias: dentistas, fisioterapeutas, enfermeiros, auxiliares de enfermagem, estagiários etc.

Sob este ângulo, pode-se concluir que o ACS é o grande operador e mediador da tecnologia leve no PSF.

\section{CONSIDERAÇÕES FINAIS}

A carga psíquica do trabalho, descrita nos depoimentos dos ACS como resultado da relação destes com a organização do trabalho e como dispositivo regulador da carga global de trabalho, refletiu a existência e o uso das aptidões (aprendidas e improvisadas) do ACS, sejam elas intersubjetivas, psicoafetivas e de conhecimento técnico sobre aquilo que produz: o cuidado comunitário.

A psicodinâmica do trabalho anuncia uma abordagem específica do sofrimento pela via da organização do trabalho. Esta pesquisa foi capaz de apreender algumas nuanças ilustrativas de um conjunto extenso de variáveis que operam no processo produtivo, na representação do significado do trabalho e na saúde mental do ACS como sujeito.

Neste estudo, as representações captadas remetem à existência de um território de tensões no trabalho cotidiano do ACS no PSF, constituído basicamente de quatro tipos de pressão sobrepostas: 1) a dos pressupostos do PSF, sob a vertente da integralidade e da responsabilização pela microárea; 2) a dos profissionais da equipe, atravessada pela necessidade de contratualidade interdisciplinar; 3) a da comunidade que interroga, interpela e reivindica seus direitos e 4) a do próprio ACS que circula pela via da fantasia, demonstrando estar entorpecido na onipotência.

A incorporação do modelo PSF ao Sistema Único de Saúde pede um amadurecimento, quanto à audácia das propostas, proporcionalmente, aos recursos disponibilizados para a real inversão do modelo assistencial em implantação na cidade de São Paulo.

O processo deve ter o propósito de rever igualmente a missão, a competência, a qualificação e a supervisão do ACS, um conjunto fundamental de elementos que pode modular a vivência da satisfação e do sofrimento na relação do ACS com a comunidade, com a equipe e consigo próprio, no intuito da produção de uma rede de sentidos, tendo em vista as dificuldades reveladas pelo presente estudo.

É preciso reconhecer que os modos de produção implícitos no trabalho do ACS ainda fazem parte de um processo muito novo, incipiente; uma configuração inédita a todos os agentes institucionais, políticos e comunitários envolvidos direta ou indiretamente na produção cotidiana do cuidado comunitário. 


\section{REFERÊNCIAS}

1. Dejours C. A loucura do trabalho: estudo da psicopatologia do trabalho. São Paulo: Cortez; 1992.

2. Codo W. Um diagnóstico integrado do trabalho com ênfase em saúde mental. In: Jacques MG, Codo W, organizadores. Saúde mental e trabalho. Petrópolis: Vozes; 2002. p. 173-90.

3. Campos GWS. Subjetividade e administração de pessoal: considerações sobre modos de gerenciar o trabalho em equipes de saúde. In: Merhy EE, Onocko R, organizadores. Agir em saúde: um desafio para o público. São Paulo: Hucitec; 1997. p. 229-66.

4. Ribeiro EM, Pires D, Blank VLG. A teorização sobre processo de trabalho em saúde como instrumental para análise do trabalho no Programa Saúde da Família. Cad Saúde Pública. 2004;20(2):438-46.

5. Brasil. Ministério da Saúde. Secretaria Executiva. Programa Agentes Comunitários de Saúde (PACS). Brasília; 2001.

6. Brasil. Ministério da Saúde. Fundação Nacional de Saúde. Programa de Agentes Comunitários de Saúde. Avaliação qualitativa do Programa de Agentes Comunitários de Saúde. Brasília; 1994.

7. Vasconcelos EM. Educação popular e a atenção à saúde da família. São Paulo: Hucitec; 1999.

8. Brasil. Ministério da Saúde. Secretaria de Assistência à Saúde. Coordenação da Saúde da Comunidade. SIAB: manual do Sistema de Informação de Atenção Básica. Brasília; 1998.
9. Brasil. Ministério da Saúde. Programa de Saúde da Família [texto na Internet]. Brasília; 2001. [citado 2003 jun. 3]. Disponível em: http://www.saude.gov.br/psf/programa

10. Dejours C. A carga psíquica do trabalho. In: Dejours C, Abdoucheli E, Jayet C. Psicodinâmica do trabalho: contribuições da Escola Dejouriana à análise da relação prazer, sofrimento e trabalho. São Paulo: Atlas; 1994. p. 21-32.

11. Seffner F. O conceito de vulnerabilidade: uma ferramenta útil em seu consultório [texto na Internet]. Canoas: UNILASALLE; 2005. [citado 2005 abr. 12]. Disponível em: http:/www.unilasalle.edu.br/seffner/artigo4.htm

12. Palmer RE. Hermenêutica. Lisboa: Edições 70; 1969.

13. Merhy EE. Em busca do tempo perdido: a micropolítica do trabalho vivo em saúde. In: Merhy EE, Onocko R, organizadores. Agir em saúde: um desafio para o público. São Paulo: Hucitec; 1997. p. 71-112.

14. Merhy EE, Chakkour M, Stéfano E, Stéfano ME, Santos CM, Rodrigues RA, et al. Em busca de ferramentas analisadoras das tecnologias em saúde: a informação e o dia a dia de um serviço, interrogando e gerindo trabalho em saúde. In: Merhy EE, Onocko R, organizadores. Agir em saúde: um desafio para o público. São Paulo: Hucitec; 1997. p. 113-50. 